trace a similar association of chorea with gout and rheunatoid arthritis, in spite of the rarity of these maladies in early life. Unquestionably the undoubted occurrence of nonrheumatic chorea offers a very serious objection to the hypothesis suggested in my paper, if it can be shown that temporary fibrous tissue overgrowth is pathognomonic of rheumatism; but I do not think that it is proved that similar changes are not produced in other diseases, even although they may not result in the formation of subcu. taneous nodules in the characteristic situations. In conclusion, I may say that I would not for a moment deny that the hypothesis at present rests upon slender foundations, but I believe that the clinical considerations upon which it is based warrant the suggestion of a line of pathological research.

I am, Sirs, yours faithfully,

Chandos-street, W., Dec. 2nd, 1889.

ARCH. E. GARROD.

\section{"MEAN DURATION OF LTFE."}

\section{To the Editors of THE LANCET.}

SiRs,-Parkes gives the following formula for calculating the mean duration of life, and at the same time condemns this quantity as a test of the health of the population considered: $\frac{2}{3}$ inverse of death-rate $+\frac{1}{3}$ inverse of birth-rate. This, when the birth-rate equals the deathrate, coincides with the formula quoted by Mr. S. C. Waters-viz, the inverse of the death-rate. The figures in Dr. Corfield's report do not agree with either of these formula, so that, as he asserts that he gives the real average duration of life walculated from the death-rate of his district, and not, as you suggested, the average age at death, it would be interesting to know the method used by him. The expression "mean duration of life" is, I hear, avoided by actuaries, but much affected by political and social orators and writers. Nothing puts an audience into a better frame of mind than telling them the mean duration of life has been increased. it is taken to mean, as Mr. Waters suggests, the expectation at birth, it is essentially yearless, and quite unfit to be employed as a test of health in any particular year. I think two things are necessary in the proper use of figures: that they should be correctly used, and also that no attempt should be made to claim for them a greater precision than the subject admits of. The death-rate itself is acknowledged to be simply a convenient expression for something that gives a rough indication of the health of a district, and any figures arrived at from this basis by means of an approximate formula must be very wide of the mark. The true statement of the case is this. The reciprocal of its deathrate is roughly proportional to the state of health of a district, and is therefore roughly proportional to the dura tion of life in that district, generally speaking. The expression " mean duration of life" applied to any particular year is scientifically meaningless and misleading to the public. I am, Sirs, yours faithfully,

Dec. 1889 T. Glover Lyon, M.A., M.D. Cantab.

\section{"BLINDNESS BY DISABILITY." \\ To the Editors of THE LANCET.}

SIRs,--You will doubtless be deluged with letters on the subject of Dr. Gowers' communication in your last edition. Dr. Gowers, who is a consummate master of that most difficult instrument, the ophthalmoscope, warmly mentions a case of optic neuritis in chlorosis which, unfortunately, was under the care of a medical man unable to use the ophthalmoscope, and terminated ultimately in blindness. It was a sad case, certainly, and it would appear that the medical attendant was greatly to blame, not in my opinion so much on account of his ignorance of the ophthalmoscope as because he failed to properly treat the chlorosis, the cause of the neuritis, with its suitable and well-known remedy-viz., iron. All physicians and surgeons who specially study the eye and its diseases must every now and then come across the unhappy results of ignorance and incompetence, and I wonder what Dr. Gowers would say to the case of a poor fellow, only forty-seven, who came to see me a few weeks back, totally blind in his left eye, and with the following history. About two years ao o he was admitted into a hospital suffering from some form of ulceration of the leg, and whilst in this institution an attack of typical acute glaucoma came on in his left eye, with severe pain and vomiting, and rapid loss of vision; no operation, he tells me, was ever suggested to him, the eye was treated with "lotion, drops, and caustic," and seven weeks from the onset of his attack he left the hospital with the sight of that eye completely gone, and when I saw him it was in a state of glaucoma absolutum, with the typical glaucoma cup, and to make matters worse, he is suffering from an old injury to his other eye, the sight of which is letters of $20 \mathrm{~J}$ aeger slowly. In my innocence I had thought that every medical man knew of the existence of acute glaucoma, and that iridectomy, done in time, is an absolute specific for it. But Dr. Gowers refers to a wider subjectthe instruction in the use of the ophthalmoscope given at the schools, and the number of the men who avail themselves of it. And here I think there is good cause for congratulation. I can myself speak for two schools. Eleven years ago I finished my hospital career in London, having, amongst other prizes, taken the medal for Practical Medicine, and I can safely say I never saw the optic disc all the time indeed, the student who even possessed such a thing as an ophthalmoscope was a rura avis. It was not con sidered the thing to go into the Eye Department, and I never felt welcome there myself; one always seemed to be intruding, at least so I thought. Later I studied at Edinburgh University, and graduated there, dividing with another the prize given to the most distinguished graduate, and yet, $I$ believe, only on one occasion had I succeeded in catching a hurried glimpse of the optic disc. I mention these facts, not in personal agorandisement, to show that only a few years ago it was possible to take the highest prizes at two large schools of medicine without being able to recognise an optic disc; yes, or the vocal cords or mem. brana tympani either. I have fortunately been able to rectify those defects, and, returning and working at both my former places of study under a new régime, I am surprised to find the number of men with a very competent. knowledge of the ocular fundus, and it would be impossible, I believe, now to take a prize for medicine at either institution without a good knowledge of the ophthalmoscope, and doubtless, ere very long, men will be unable to graduate at any university in the United Kingdom without being able to diagnose the various common diseases of the fundus of the eye. I am, sirs, yours obediently,

Norwich, Nov, 25th, 1889 .

$$
\text { S. JOHNSON TAYLOR, M.B., M.R.C.S. }
$$

\section{THE MORTON LECTURE ON CANCER.}

\section{To the Editors of THE LAANCET.}

SIrs,--I am pleased to find that Dr. Inglis Parsons hass reason to think that his operation may be effective at fewer sittings than I supposed, or even at a single sitting. I am quite satisfied that he has been before me in publishing the opinion that cancer cells escape the control of the nervous system, for I have never published any of my views on cancer; but that these latter are entirely independent, and, more than that, may turn out to be incorrect, is what $I$ am equally ready to maintain. I will explain my views, and the processes by which $I$ arrived at them, in a note to the Morton Lecture, when this is published.

I am, Sirs, yours truly,

Savile-row, W., Dec. 2nd, 1889. John Marsifali.

\section{OPERATIVE TREATMENT OF FLAT-FOOT.}

To the Editors of THE LANCET.

SIRs,-It has been strongly urged upon me that, if I still hold osteotomies for flat-foot to be unwarranted, because unnecessary, I ought not to allow Mr. Hare's paper in THE LANCET of Nov. 16th to pass unnoticed. But I have felt, as I did on reading Mr. Davy's communication to the Medical Society in March last, that if the facts and considerations which, during the past six years, I have repeatedly laid before your readers have not convinced, neither would anything for which I could reasonably ask you to spare me space be likely to do so now. Moreover, have recently stated at full length, in a published book, my views on the physiology of the feet. Therein I have attempted to prove, among other propositions, these, which I first propounded more than sixteen years ago:-1. The muscles that by their action move the foot and the body upon it, in their action support the arch, which, in early life, they develop. 2. Flat-foot is due to failure of this functional support; renewal of functions in specially active manner will restore the arch. As, however, in my book I 